and relevant (making the peculiarly old-fashioned photograph on the front cover rather mystifying for such current scholarship). Although there is sometimes a weary sense of 're-inventing the wheel' about some of the subject matter of this collection it is only because we are still debating subjects and issues that were being studied in the 1970s. Despite that, this book is both engaging and interesting, a coherent collection which would be of interest to academics and students in media and cultural studies, leisure studies, gender studies, anthropology, and sociology.

doi:10.1057/palgrave.fr. 9400395

Samantha Holland

\title{
Workable sisterhood: the political journey of stigmatized women with HIV/AIDS
}

Michele Tracy Berger; Princeton University Press, Princeton and Oxford, 2004, 234p, ISBN 0-691-11853-1, £11.95

Much of the current literature on gender and HIV/AIDS is concerned primarily with the causes of infection and the implications of these for prevention. It explores the interaction between women's greater biological vulnerability and the gender inequalities that often place severe constraints on their ability to protect their own health. Only recently have researchers begun to focus on the experience of living with HIV/AIDS and how this differs for women and men. This book makes an important contribution to that literature.

The book reports on an ethnographic study of a group of women whose lives were radically changed by a diagnosis of HIV/AIDS. But it is not an account of fear and despair. Of course, most of the participants reported deep distress on discovering their status. But they went on to reconstruct their identities and their ways of living, finding their public voices through community action designed to make a change for themselves and others.

Sixteen women participated in the study that was carried out in inner city Detroit. They were primarily women of colour and were already 'social deviants' before becoming infected. Their early lives are described as 'troubled, difficult, unmanageable and depressing'. They were sex workers, drug users and law breakers when they contracted what is often seen as a socially unacceptable disease. According to the author, this placed them in a situation of what she calls 'intersectional stigma'. 
Discussions of 'intersectionality' are increasingly common in feminist theoretical debate but they often remain at a high level of abstraction. This study makes a valuable contribution to these debates through operationalizing the concept at both social and individual levels. Linking intersectional oppression with the experience of stigma, Berger provides an innovative framework for the interpretation of empirical findings on HIV-positive women in a specific social setting.

These women are part of a large group who represent the new face of HIV/AIDS in the US. They became infected in a context of race, class and gender subordination where they were already seen as marginal to society. The diagnosis itself initially exacerbated their situation and many of the women reported increased drug use in the immediate aftermath. But when they achieved greater understanding of their personal histories of socially constructed injustices and stigma many were able to reshape their situation in more positive ways.

Much of this new awareness came either directly or indirectly from the HIV diagnosis itself which Berger describes as a 'dramatic catalyst to their lives'. The women talked with considerable anger about the discrimination that they experienced in their treatment. Many resented the way the diagnosis itself was imparted to them with little sensitivity or support. But after the initial shock, most chose to tackle their drug use and to find an alternative to sex work. This involved complex and challenging processes of personal and social change in which relapses were common.

As Berger puts it, 'life reconstruction is not a perfect, complete nor linear process'. In her attempt to model these changes she highlights both the external resources the women eventually learned to utilize and the internal resources they developed for themselves. Much of this empowerment came from the experience of substance abuse recovery programmes and especially from therapeutic work on sexual abuse. Although the women were often highly critical of these programmes and of other participants, they did develop a range of new understandings and skills that 'empowered' them in a number of ways.

Many became involved in both paid and unpaid community work. Berger integrates her description of these activities into a valuable discussion of the gender dimensions of formal and informal political action. She describes three overlapping roles of advocate, activist and helper which the women used to try and effect change in the lives of those similar to themselves. However, she also points out that these activities are part of the women's own survival strategies in the face of a potentially life-threatening disease.

Berger provides a compelling account of her subjects' trajectories while at the same time offering a sensitive and reflexive account of her own experience of the research process. She acknowledges for example, her own anxieties and fears as she hung around the Thirty Sixth District Courthouse in the early days of 
fieldwork. In later stages she became closely involved in many of the women's lives but retained a rigorous approach to the theoretical, conceptual and ethical quandaries that lay at the heart of the study.

This is an important book. Of course, the small sample it describes is not representative of HIV positive women in general or even of those in the USA. As Berger herself points out, the women were self selected and were healthy at the time of interview. But the analysis provides fertile ground for further work in a number of different areas. As anti-retroviral drugs become more effective, HIV is increasingly becoming a chronic illness instead of a terminal disease, at least in those countries where they are available. This highlights the importance of further studies of this kind that explore the HIV experience in gender sensitive ways across a range of different social, economic and cultural settings.

doi:10.1057/palgrave.fr. 9400401

Lesley Doyal

\section{Sistering: power and change in female relationships}

Melanie L. Mauthner; Palgrave Macmillan, Houndmills, Basingstoke, Hampshire, 2002, 240p, ISBN 1-4039-4125-4/GBP 15.99 (Pbk)

Melanie L. Mauthner began her research on biological sister relationships in 1993 when she observed that work on sistering was notable for its absence in academic studies and social policy. She states that 'one paradox about sistering is that, although it is a widespread female experience, sistering practices remain largely invisible' (p. 13). Mauthner's qualitative approach to her research eventually led to writing her dissertation on the topic. Sistering: power and change in female relationships is the book adaptation of that dissertation. I was first drawn to this work because I am the eldest of five siblings: I have three brothers and one sister. Over the years my relationship with my sister has weathered many of the changes chronicled by Mauthner. My sister Jeanette and I were born fifteen months apart and we have spent the last fifty-six years serving as sisters to each other. I learned a great deal about my sister self in reading this text.

Feminist theory provides a framework for the research. The data were collected using an autobiographical approach. Mauthner draws upon both standpoint and post-structuralist theory in analysing the data she collected. The major questions that Mauthner explores are: 'What is sistering and what are women's experiences of it?' (p. 1). Early on, Mauthner establishes the boundaries of her work: 